\title{
Mathematical Model Development Using Commercial Polypropylene to Evaluate Degradation of Plastic Under the Thermal Fatigue Cycles; Modelling approach.
}

\author{
L.P.S. Rohitha ${ }^{1}$, S.S.N.Perera ${ }^{2}$, M.A.B.Prashantha ${ }^{3}$ \\ ${ }^{1}$ University of Moratuwa, Department of Earth Resources Engineering. Sri Lanka, \\ ${ }^{2}$ University of Colombo, Research \& development Centre for Mathematical Modelling, Department of \\ Mathematics, Sri Lanka \\ ${ }^{3}$ University of Sri Jayewardenepura, Department of Chemistry. Sri Lanka
}

\begin{abstract}
Recycling of waste plastics is of great interest in solid waste management and characterization of waste plastic. The change of stress-strain behaviour of waste plastic depends on environment factors and the number of days exposed to heating at day time and cooling at night. Stress-strain behaviour of commercial grade polypropylene at the end of each thermal fatigue cycles was studied. Heating-cooling cycle was set to 8 hours for heating at a specified temperature $\left(80^{\circ} \mathrm{C}, 100^{\circ} \mathrm{C}, 120^{\circ} \mathrm{C} 140^{\circ} \mathrm{C}\right.$ and $160^{\circ} \mathrm{C}$ ) and air cooling over night at ambient temperature. Toughness of each sample was calculated in two different ways, in one method it was calculated using regression equation based on stress values of strains at $0.5 \%, 1 \%$, yield point, breaking point and strains at one third and two third of plastic region. In the other method, the geometrical area of the stress-strain curve was calculated using yield stress, breaking stress, elastic limit, young modules. Matching ratio of toughness ( $\beta)$ is defined as a new index to calculate the ratio of toughness calculated from regression equation and parameters of stress-strain curve. The percentage of relative difference of matching ratio $(\gamma \%)$ of toughness is defined as another index. It is defined with respect to the matching ratio of commercial polypropylene samples without exposing to the thermal fatigue conditions $\left(\beta_{0}\right)$.The percentage of the retention of plastic behaviour (RPB \%) of commercial plastic product is defined as another index. It can be calculated when $\beta_{0}$ is known. The proposed model can be used to calculates retention of plastic behaviour (RPB\%) as a percentage with respect to the original state under the natural condition.
\end{abstract}

Keywords: matching ratio, thermal fatigue, polypropylene, Toughness of plastics, Degree of degradation.

\section{Introduction}

Expansion and contraction is a natural phenomenon common to any system with temperature fluctuation in nature. Thermal energy is the main driving force in natural expansion-contraction cycles of materials. Heating and cooling is usually regular in tropical countries and hence natural expansioncontraction during the day and night is an inherent regular process for the materials exposed to the natural environmental conditions of Sri Lanka.

The degree of microscopic change in plastic materials depends on the amount of thermal energy dispersed throughout the mass during the heating and cooling process in day and night. Leaching and evaporation of organic additives in commercial plastics is one of the main events during expansion while heating [1]. The mechanism of the loss of volatile compound (oraganic additives and monomer residues) in the plastic matrix consists diffusion up to the interface and loss to the environment through evaporation, extraction or migration [1]. It leads to weight loss and hence develop microscopic cavities and channels within the plastic matrix. Cumulative ef microscopic changes affect to the physico-mechanical properties when it exceed the threshold. The modulus of plastic in the region of strain hardening at different temperatures, the effect of molecular orientation to on the stress-strain behaviour and microscopic changes during the stress-strain deformation were extensively studied [2-4]. However the change in stress-strain behaviour of plastics under the thermal fatigue cycles (heating - cooling cycles) was not extensively studied. The aim of this paper is to develop a mathematical model based on stress-strain curve under the thermal fatigue cycles to calculate the degree of degradation of plastic and percentage of weight loss of waste plastic aged in natural heating cooling cycles during day and night. 
Theory

\section{Material and Methods}

The area of stress-strain curve represents the toughness and it can be calculated using the regression equation of the stress-strain curve or using the parameters (yield stress, braking stress, plastic limit, elastic limit, young modules) of stress -strain curve [4]. Figure 1 shows selected strains at $0.5 \%$ $\left(\varepsilon_{0.5}\right), 1 \%\left(\varepsilon_{1}\right)$, yield point $\left(\varepsilon_{\mathrm{y}}\right)$, breaking point $\left(\varepsilon_{\mathrm{b}}\right)$ and strains at one third $\left(\varepsilon_{1 / 3}\right)$ and two third $\left(\varepsilon_{2 / 3}\right)$ of plastic region.Mathematical relationship between tensile stress and strain follows the $\mathrm{n}^{\text {th }}$ order polynomial function $(f(\mathrm{x}))$ when the stress-strain behavior is comparable with the typical curve showed in Figure 1. The output of equation gives the area under the curve given in Figure 1 at the limit of $\varepsilon=0$ to $\varepsilon=\varepsilon_{\mathrm{b}}$

$$
\text { Area under the curve in figure } 1=\int_{0}^{\varepsilon_{b}} f(x) d x
$$

In the second method, the geometrical area of the stress-strain curve was calculated using yield stress, breaking stress, elastic limit, and Young modules. As shown in Figure 1, the point " $S$ " represents strain at yield point, the point " $R$ " represents strain at breaking point, the value at $\sigma_{y}$ represents yield stress at point $\mathrm{P}$ (represents yield point) and value at $\sigma_{\mathrm{bp}}$ represents breaking stress at point $\mathrm{Q}$.

Toughness $(\mathrm{Ts})=$ Area under the curve

$$
\begin{aligned}
= & \text { Area of } P Q R T \\
= & P S T \text { area }+P Q R S \text { area } \\
= & \frac{1}{2}[(T S \times P S)+(S R)(P S+Q R)] \\
& P S=T S \text { tan } \alpha
\end{aligned}
$$

Young modules at elastic region is given by $\tan \alpha$ and PS in equation 1 is replaced by TS $\tan \alpha$.

$$
=\frac{1}{2}\left[\left(S^{2} \tan \alpha\right)+S R(\mathrm{ST} \tan \alpha+Q R)\right]
$$

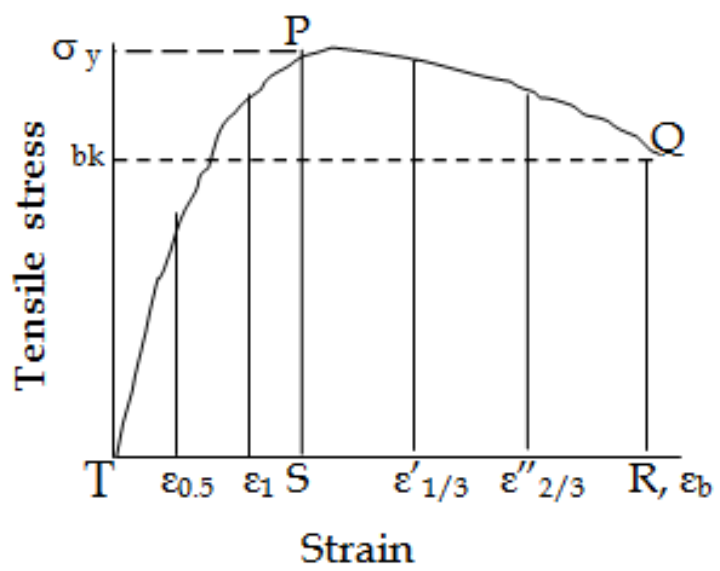

Figure1. Stress strain curve for Polypropylene material.

Toughness $=\frac{1}{2}\left[\left(T S_{y}^{2} \times\right.\right.$ Young's modules $)+S R((T S \times$ Young's module $\left.)+Q R)\right]$

Strain at yield point $\left(\varepsilon_{y}\right)$ can be used to replace the TS in equation 2.

Toughness $=0.5\left[\left(\varepsilon_{y}{ }^{2} \times\right.\right.$ Young's module $)+\mathrm{SR}\left(\left(\varepsilon_{y} \times\right.\right.$ Young's modules $)+$ Breaking stress $\left.)\right]$

$\mathrm{SR}=\Delta \varepsilon=$ Stain at breaking point $\left(\varepsilon_{\mathrm{b}}\right)$ - Strain at yield point $\left(\varepsilon_{\mathrm{y}}\right)$ and breaking stress is given by $\sigma_{\mathrm{b}}$ 
Toughness $=\frac{1}{2}\left[\left(\varepsilon_{y} \times\right.\right.$ Young's module $\left.) \times\left(\varepsilon_{y}+\Delta \varepsilon\right)+\left(\sigma_{y} \times \Delta \varepsilon\right)\right]$.

The equation (4) represent toughness (Ts) in terms of Young's modules (E) strain at plastic limit ( $\Delta \varepsilon$ ), strain at yield point $\left(\varepsilon_{\mathrm{y}}\right)$ and point $\left(\sigma_{\mathrm{b}}\right)$

$$
\text { Ts }=0.5\left[\left(\varepsilon_{y} \times E\right) \times\left(\varepsilon_{y}+(\Delta \varepsilon)+\sigma_{b . s} \times(\Delta \varepsilon)\right)\right]
$$

The ratio of the total area calculated from the regression equation $\left(\mathrm{A}_{\mathrm{reg}}\right)$ to the area calculated using the parameters of stress-strain curve can be defined as matching ratio of toughness $(\beta)$. Usually $\left(\mathrm{A}_{\text {reg }}\right)$ is greater than the $\left(\mathrm{A}_{\mathrm{par}}\right)$ and the area of the curve is a function of degree of degradation.

$\beta=\frac{A_{\text {reg }}}{A_{\text {par }}}$

Mechanical properties of plastic are function of thermal history [5]. Matching ratio ( $\beta$ ) of toughness of commercial plastic material with change with the thermal fatigue conditions and hence equation (6) given below defines the percentage of relative difference of matching ratio (PRDMR, $\gamma \%$ ) as a new parameter to determine the degree of degradation.

$\gamma \%=\frac{\left(\beta_{0}-\beta_{t}\right) \times 100}{\beta_{0}}$

Where,

$\beta_{0}=$ Matching ratio before exposing thermal fatigue

$\beta_{t}=$ Matching ratio after the thermal fatigue at a defined temperature after $\mathrm{i}^{\text {th }}$ cycle.

The equation (7) calculates the percentage of weight loss ( $\alpha \%)$ where, $W_{o}$ is initial mass, $W t$ is the mass at time " $\mathrm{t}$ " and $W_{f}$ is the final mass [7-12]. The equation (8) shows the loss of weight $\left(\frac{W_{0}-W_{t}}{W_{0}}\right)$ with respect to the in terms of weight loss and ratio of $\mathrm{W}_{\mathrm{f}}$ to $\mathrm{W}_{0}$.

$$
\begin{aligned}
& \alpha=\frac{W_{\mathrm{O}}-W_{t}}{W_{\mathrm{O}}-W_{f}} \times 100 \% \\
& p=\left(\frac{W_{0}-W_{t}}{W_{0}}\right)=\alpha\left(1-\frac{W_{f}}{W_{0}}\right) \cdots \cdots
\end{aligned}
$$

\section{Experiment}

Polypropylene plastic boxes used in ice cream industry were selected in this study as a model material since the polypropylene is one of major plastic material in plastic waste. A flat area having $\mathrm{n}$ average thickness of $0.2 \mathrm{~mm}$ was selected and tensile test samples in dumbbell-shape [6] $(30 \times 150 \mathrm{~mm})$ were prepared for triplicate analysis at the end of each thermal fatigue cycle at fixed temperature.

Thermal fatigue cycle was set to 8 hours for heating at a fixed temperature $\left(80^{\circ} \mathrm{C}, 100^{\circ} \mathrm{C}, 120^{\circ} \mathrm{C} 140^{\circ} \mathrm{C}\right)$ and 16 hours for air cooling over night at ambient temperature. Weight loss and stress-strain behaviour were studied at the end of each cycle by using TMS 1300 tensile testing machine. Toughness of each sample was calculated in two different ways using stress-strain values. In the first method, is we determine the regression equation using MATLAB software.

\section{Results and Discussion}

Figure 2 shows change in stress-strain curves of commercial polypropylene samples at the end of thermal fatigue cycles at $140^{\circ} \mathrm{C}$. As shown in Figure 2, stress-strain behaviour of test samples depends on the number of thermal fatigue cycles at the heating temperature. Yield strength, breaking strength, young modules and rigidity have increased with the number of thermal fatigue cycles. Strain at breaking point has decreased with the number of thermal fatigue cycles. 


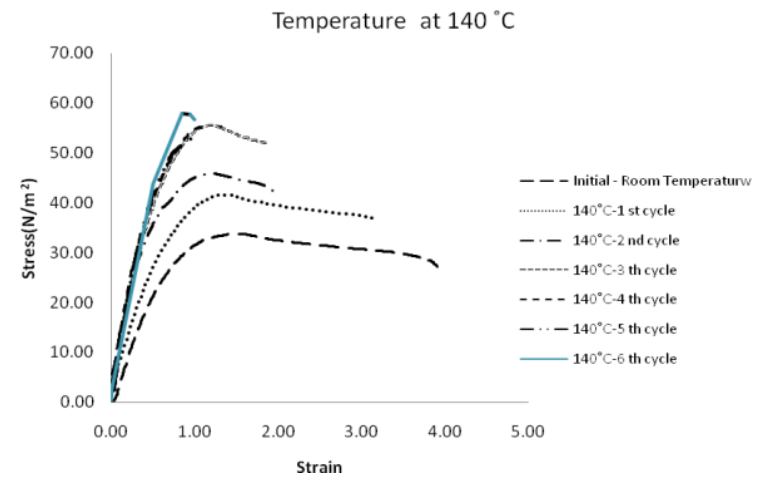

Figure 2. Stress - strain curves at $140^{\circ} \mathrm{C}$

Figure 3 shows the weight loss at the end of thermal fatigue cycles at different heating temperature. Maximum of loss of weight with respect to the initial weight was found to be $2.56 \%$. Disappearance of plastic limit is a significant change in commercial plastic material as shown in figure 2, elastic limit has disappeared at the end of $6^{\text {th }}$ thermal fatigue cycle at the heating temperature $140^{\circ} \mathrm{C}$. The loss of weight (p) and weight loss at that point were $1.73 \%$ and 0.64 respectively. It indicates the effect of loss of low molecular weight substances from the plastic matrix on mechanical properties of plastic. Loss of flexibility and increasing in rigidity during the thermal fatigue cycles indicate the loss of plasticisers and microscopic changes including compacting pattern of polypropylene molecules and cavity density during the thermal fatigue cycles.

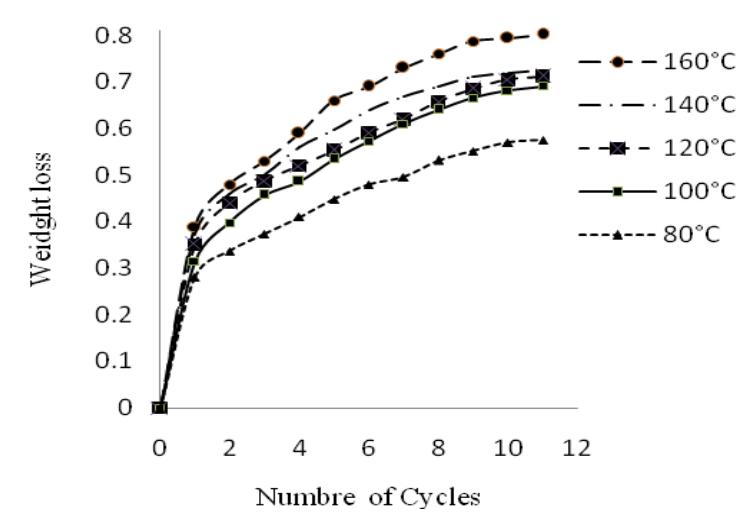

Figure 3. Percentage of weight loss

Figure 4 shows the behaviour of the matching ratio of toughness with the number of thermal fatigue cycles at different heating temperature. It indicates that the matching ratio of toughness closes to unity as the number of thermal fatigue cycles increases at a constant heating temperature.

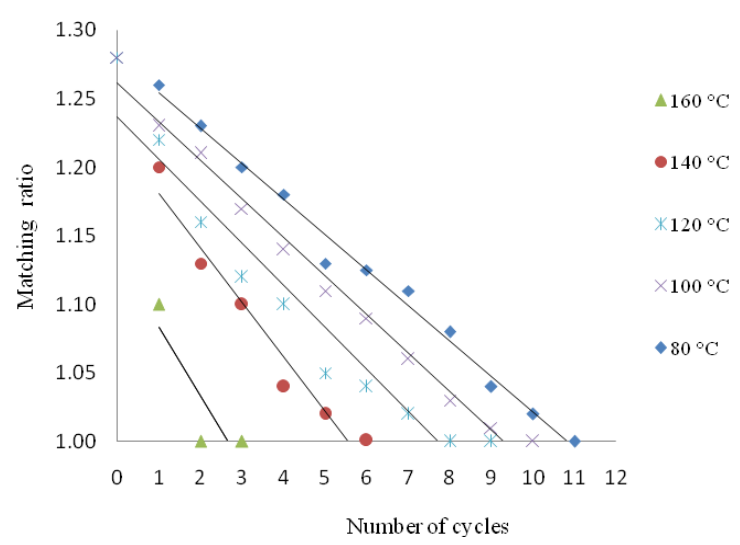

Figure 4. Matching ratio of toughness with the number of thermal fatigue cycles. 
As shown in figure 4 matching ratio of toughness shows a liner relationship with number of fatigue cycles at $100^{\circ} \mathrm{C}$ and below. Table 1 shows the correlation at $80^{\circ} \mathrm{C}$ to $140^{\circ} \mathrm{C}$ temperature.

Table 1: The highest correlation at $80^{\circ} \mathrm{C}$ to $140^{\circ} \mathrm{C}$ temperature.

\begin{tabular}{|l|l|l|}
\hline $\begin{array}{l}\text { Temperature } \\
\left({ }^{\circ} \mathrm{C}\right)\end{array}$ & $\begin{array}{l}\text { Number of cycles required to reach } \\
\text { unity }\end{array}$ & Correlation coefficient \\
\hline $80^{\circ} \mathrm{C}$ & 11 & 0.9996 \\
\hline $100^{\circ} \mathrm{C}$ & 9 & 0.9986 \\
\hline $120^{\circ} \mathrm{C}$ & 8 & 0.9926 \\
\hline $140^{\circ} \mathrm{C}$ & 6 & 0.9956 \\
\hline
\end{tabular}

Number of thermal fatigue cycles required for matching ratio of toughness to reach the unity is high at $80^{\circ} \mathrm{C}$ heating temperature compared to the heating temperature at $160^{\circ} \mathrm{C}$. Matching ratio of toughness is equal to unity when the geometrical area calculated from the parameters of stress-strain curve closes to the total area calculated from the regression equation. The matching ratio of plastic considered as an index to indicate the effect of thermal fatigue cycles to the disappearance of the functions of plasticizers in plastic materials. Figure 5 shows behaviour of PRDMR $\left(\Upsilon_{\max }\right)$ with the number of thermal fatigue cycles. As shown in figure 5 PRDMR has reached to a maximum $\left(\Upsilon_{\max }\right)$ with number of thermal fatigue cycles and not the magnitude of maximum is not a function of heating temperature.

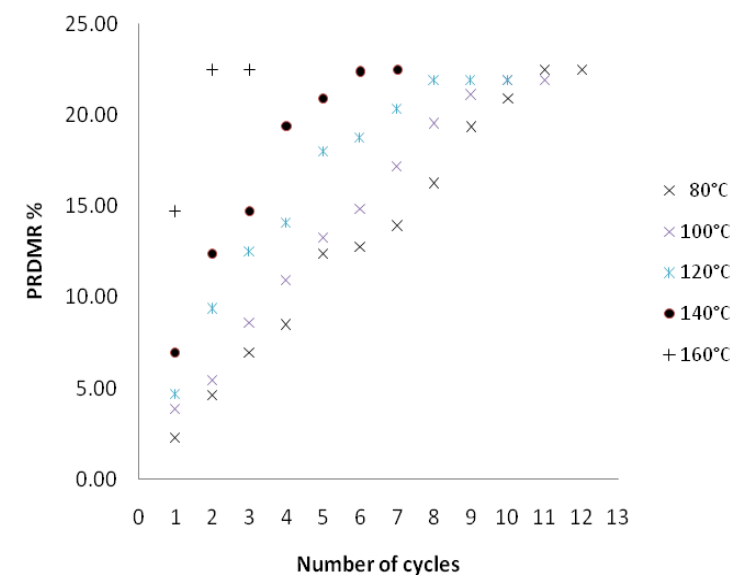

Figure 5. Variation of PRDMR with the number of thermal fatigue cycles.

Figure 6 shows the liner relationship between the numbers of cycles required to reach the $\Upsilon_{\max }$ with heating temperature. The maximum percentage of relative deference of matching ratio $\left(\Upsilon_{\max } \%\right)$ can be defined as disappearance point of plastic behaviour from the original state of the commercial polypropylene sample. The curves at $80^{\circ} \mathrm{C}, 100^{\circ} \mathrm{C}, 120^{\circ} \mathrm{C}, 140^{\circ} \mathrm{C}$ and $160^{\circ} \mathrm{C}$ temperatures indicate the disappearance point of plastic behaviour of the commercial polypropylene product as $22.5 \%$.

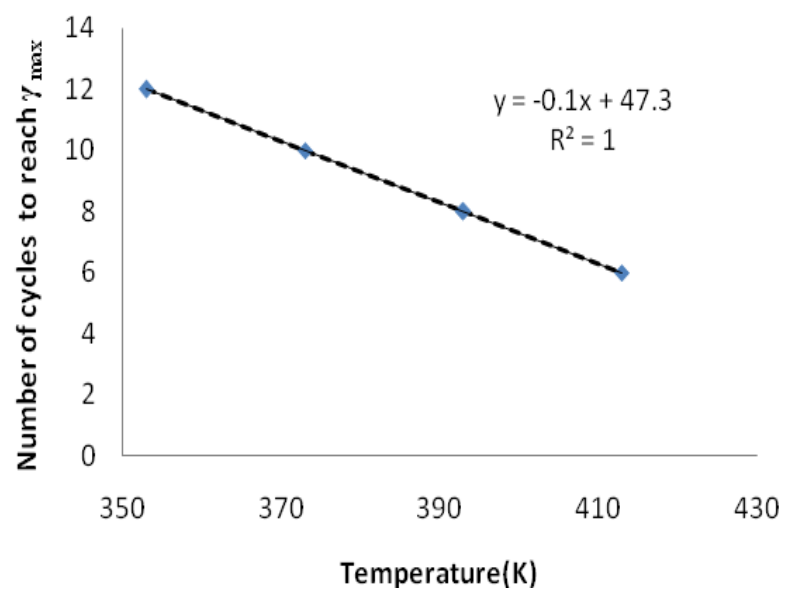

Figure 6: Liner relationship between the numbers of cycles required to reach the $\Upsilon_{\max }$ 
Equation 9 is the regression equation to calculate the number of thermal fatigue cycle to reach $\Upsilon_{\max } \%$,

$$
\Upsilon_{\max } \%=-0.1 \mathrm{~T}+47.3 \text {....... }
$$

Commercial polypropylene reached to the maximum of $\left(\Upsilon_{\max }\right)$ at $160^{\circ} \mathrm{C}$ at the end of second cycle and the end of eleventh cycle at $80^{\circ} \mathrm{C}$. The percentage of the Retention of Plastic Behaviour (RPB \%) of commercial plastic product can be defined using $\Upsilon$ and $\Upsilon_{\max }$ as shown in equation (11).

Retention of plastic behaviour $(\%)=\left(1-\frac{\gamma}{\gamma_{\max }}\right) \times 100 \%$

Figure 7 shows the linear relationship between RPB\% with the number of thermal fatigue cycles under the natural environmental conditions. Natural thermal fatigue cycle is defined as heating period of day time and cooling period overnight. The percentage of the retention of plastic behaviour is close to zero when the number of cycles (days) is close to 400.

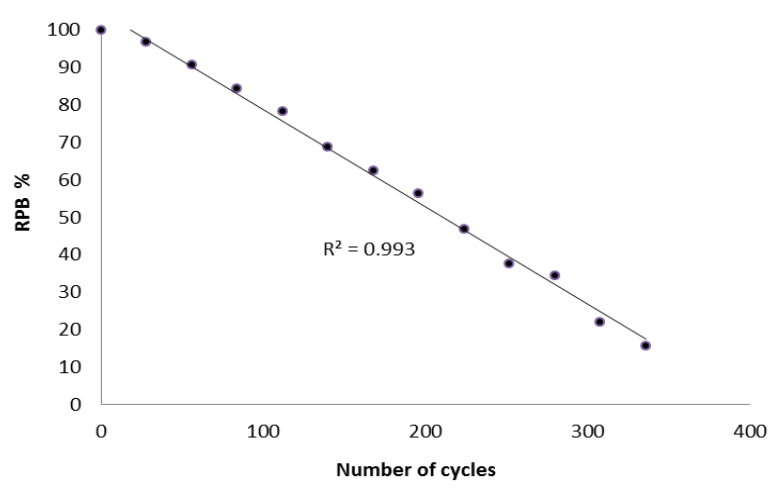

Figure 7. Variation of RPB\% with the number of fatigue cycles under the natural conditions.

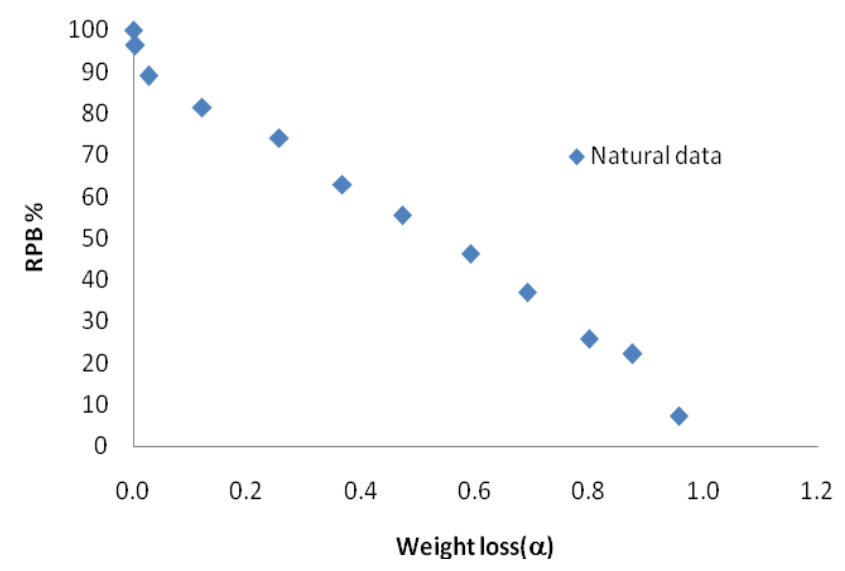

Figure 8. Variation of RPB\% with n power of weight loss at natural condition.

The equation 12 below the regression equation to calculate RPB\% with number of days under natural condition

RPB $\%=-100 \alpha+100$

The percentage of retention of plastic behaviour in under the natural condition show linear relationship with a $\boldsymbol{n}$ power of weight loss. The highest correlation with the power value is 2.2 with correlation coefficient. The equation (13) is developed using regression equation to calculate the weight loss of commercial polypropylene material using the RPB\%.

Weigh loss $=\sqrt[2.2]{\frac{(100-R P B \%)}{K}}$

The $\mathrm{n}^{\text {th }}$ power was determined using mathematical program utilized linearity property between two parameters. 


\section{Conclusion}

Heating at day time and cooling overnight is considered as a natural process of thermal fatigue. The very low percentage of weight loss has significantly affected to the stress-strain behaviour under the thermal fatigue conditions. The matching ratio of commercial plastic material $\left(\beta_{0}\right)$ becomes important index to calculate $(\Upsilon)$. The $\left(\Upsilon_{\max }\right)$ and $\left(\beta_{0}\right)$ of commercial become in a significant indices to calculate RPB \%. The percentage of RPB of waste polypropylene can be calculated using the stress-strain behaviour, $\beta_{0}$ and $\Upsilon_{\max }$. The percentage of weight loss of waste plastic can be calculated using the stressstrain curve and these two new indices.

\section{References}

[1]. Senol, S., and Pasa, Y., 2005, Effect of testing parameters on the mechanical properties of pp random copolymer, Polymer testing, Vol.24, pp-613-619.

[2]. K. Schneider, L. Häussler and S.V. Roth (2012). Tailoring of Morphology and Mechanical Properties of Isotactic Polypropylene by Processing Polypropylene, ISBN: 978-953-51-0636-4, InTech, DOI: 10.5772/38895.

[3]. Strait, L. H. Thermo-Mechanical Fatigue of polymer matrix composites. Technical report, The Pennsylvania state university, Applied research laboratory, P.O Box 30, State College, PA 16 804. 1994 Oct,

[4]. David, R. Stress-strain curves, Ddepartment of Materials Science and Engineering Massachusetts Institue of Technology, Cambridge, MA 02139, 2001 Aug.

[5]. Sri Lanka Custom (2011), Import / Export data system, Sri Lanka Custom, Colombo.Available at: http://www. customs. gov.lk/stat.htm. Accessed 20 May 2011

[6]. Flynn, J. H. in: "Encyclopedia of Polymer Science and Engineering”, H. F. Mark, N. M. Bikales, C. V. Overberger, J. I. Kroschwitz, Eds., John Wiley \& Sons, New York,1989,Suppl. Vol., p. 690.

[7]. Roy, P.K. Thermal degradation studies of LDPE containing cobalt stearate as pro-oxidant. Express Polymer Letters vol.1(2007), 208-216

[8]. Kissinger, H. E., Anal. Chem., 1957, 29, 1702-1706.

[9]. Flynn, J. H., Wall, L. A., J. Polym. Sci. Part B: Polym. Lett., 1966,4, 323 -328.

[10]. Friedman, H. L., J. Polym. Sci. Part C, 1965, 6, 183-195.

[11]. Van Krevelen, D. W., Heerden, C. V., Huntjens, F. J., Fuel, 1951,30, 253

[12]. Coats, A. W., Redfern, J. P., J. Polym. Sci. Part B: Polym. Lett., 1965, 3, 917-920 